\title{
Pemberdayaan Kelompok Perempuan Pesisir Kelurahan Bahu Dalam Diversifikasi Produk Hasil Perikanan
}

\author{
Helen Jenny Lohoo $^{1 *}$, Joyce Christiana Valencia Palenewen ${ }^{1}$ \\ ${ }^{1}$ Program Studi Teknologi Hasil Perikanan, Fakultas Perikanan dan Ilmu Kelautan, \\ Universitas Sam Ratulangi Manado, 95115, Sulawesi Utara, Indonesia \\ *Penulis korespondensi. Email: helen_lohoo@unsrat.ac.id
}

\begin{abstract}
ABSTRAK
Mitra sasaran program ini adalah Kelompok perempuan Kelurahan Bahu Lingkungan 1 Manado yang secara geografis terletak di pesisir pantai dengan potensi perikanan laut yang potensial untuk dikembangkan. Ikan tongkol merupakan salah satu jenis ikan yang paling banyak tertangkap di perairan Manado yang produk diversifikasi olahannya masih sangat terbatas. Tujuan program ini yaitu memberdayakan kelompok Wanita Nelayan Kelurahan Bahu Lingkungan 1 Manado dalam mengolah /diversifikasi produk ikan tongkol menjadi abon. Metode pelaksanaan program ini adalah focus group discussion (FGD), penyuluhan dan pelatihan. Pembuatan abon merupakan salah satu alternatif pengolahan ikan. Hal ini dilakukan untuk mengantisipasi kelimpahan produksi dan untuk penganekaragaman produk perikanan. Berdasarkan SNI 01-3707-1995, abon merupakan hasil pengolahan yang diolah dengan cara perebusan/pengukusan, penggorengan dan pengepresan atau penirisan minyak. Proses pengolahan bahan baku yang telah ditambahkan bumbu-bumbu untuk meningkatkan cita rasa dan memperpanjang daya simpan. Jenis ikan yang dibuat abon adalah ikan tongkol dan jenis ikan pelagis lainnya seperti ikan malalugis yang banyak terdapat di perairan Sulawesi Utara. Hasil dari kegiatan ini adalah peningkatan skill dan pengetahuan atau keberdayaan kelompok ibu-ibu dalam pengolahan/diversifikasi produk hasil perikanan yaitu abon ikan yang enak dan disukai panelis yang dikemas praktis. Adanya kegiatan ini diharapkan kaum wanita yang ada di daerah pesisir kelurahan Bahu Lingkungan 1 dapat diberdayakan melalui kegiatan ekonomi yang berbasis usaha perikanan sehingga menjadi lokomotif baru dalam membawa ekonomi masyarakat nelayan yang lebih baik.
\end{abstract}

Kata Kunci: Pemberdayaan, Abon ikan, diversifikasi

\section{ABSTRACT}

The target partner of this program is the Women's Group of the Kelurahan Bahu Lingkungan 1 Manado which is geographically located on the coast with the potential for marine fisheries to be developed. Tongkol fish is one of the most common types of fish caught in Manado waters, whose processed diversification products are still very limited. The aim of this program is to empower a group of women fishermen in the Manado Neighborhood 1 Village in processing / diversifying tuna products into shredded fish. The method of implementing this program is focus group discussion (FGD), counseling and training. Making shredded fish is an alternative for fish processing. This is done to anticipate the abundance of production and to diversify fishery products. Based on SNI 01-3707-1995, shredded is the 
result of processing that is processed by boiling / steaming, frying and pressing or draining the oil. The processing of raw materials that have been added with spices to improve taste and extend shelf life. The types of fish that are made of shredded fish are tuna fish and other types of pelagic fish such as malalugis fish which are widely found in North Sulawesi waters. The result of this activity is an increase in skills and knowledge or empowerment of groups of women in the processing / diversification of fishery products, namely delicious shredded fish that are liked by panelists who are packaged practically. It is hoped that this activity is expected that women in the coastal areas of Bahu Lingkungan 1 sub-district can be empowered through fisheries-based economic activities so that they become a new locomotive in bringing a better economy to fishing communities.

Keywords: Empowerment, Shredded fish, diversification

\section{PENDAHULUAN \\ Analisis Situasi}

Bagi warga masyarakat Provinsi Sulawesi Utara khususnya di Kota Manado lebih khusus lagi di Kelurahan Bahu lingkungan 1 yang berada di pesisir pantai adalah keluarga nelayan tradisional, sejak reklamasi pantai tekanan krisis memang terasa makin berat ketika jumlah ikan yang ada diperairan sekitar mereka makin lama makin jauh. Kondisi sumber daya laut di sekitar perairan Manado umumnya sudah over exploited. Nelayan tradisional yang hanya mengandalkan teknologi sederhana, sebagian besar mengaku hasil tangkapan mereka makin lama makin menurun. Dalam menghadapi ketidakpastian lingkungan laut, berbagai usaha dilakukan oleh nelayan untuk beradaptasi. Dengan ketidakberdayaan yang dialami, maka para nelayan berupaya untuk selalu meningkatkan pendapatannya. Berbagai cara yang ditempuhantara lain adalah berusaha untuk meningkatkan hasil tangkapan yang lebih banyak dan yang mempunyai nilai ekonomi tinggi, serta mencari peluang pasar yang lebih menguntungkan atau dengan melakukan penangkapan ke daerah penangkapan yang jauh dari daerah tempat tinggal mereka.

$$
\text { Lingkungan fisik nelayan }
$$

mempunyai karakteristik yang berbeda dengan petani. Sumberdaya perikanan mempunyai sifat sulit diramal serta sasaran target operasi penangkapannya hidup dan liar. Hal ini membuat usaha perikanan mempunyai resiko kerusakan dan kerugian yang tinggi serta pola pendapatan yang fluktuatif. Kenyataan tersebut memberikan dampak bagi desa pesisir yaitu kemiskinan. Sumber daya pesisir atau laut dengan produktifitas yang tinggi diharapkan berperan penting dalam mengatasi kemiskinan.

Pemerintah terus memperkuat sektor kelautan dan perikanan karena berperan penting dalam mewujudkan kemandirian ekonomi di Sulawesi Utara (Sulut). Pada 2017, produksi perikanan tercatat 818.192,3 ton atau meningkat $5,99 \%$ dibanding tahun sebelumnya sebesar $771.880,28$ ton.

Sedangkan konsumsi sebesar 58,88 $\mathrm{kg} / \mathrm{kapita} /$ tahun meningkat $0,41 \%$, dan ekspor komoditi perikanan mengalami kenaikan dari 20.734.344,37 $\mathrm{kg}$ menjadi $22.161 .387,81 \mathrm{~kg}$ di tahun 2017.

Sektor kelautan dan perikanan menjadi salah satu program prioritas pembangunan daerah. Karena ini menjadi prioritas guna mewujudkan kedaulatan pangan dalam menunjang berbagai sektor pembangunan lainnya.

Permasalahan mitra yang dirangkum berdasarkan hasil FGD antara lain:

1. Belum adanya diversifikasi produk ikan tongkol/deho. Umumnya langsung dijual 
dalam bentuk segar, dijual langsung ke pasar, dengan cara dijajakan di atas meja pada kondisi seadanya yaitu tanpa menggunakan es. Pada musim ikan hasilnya melimpah sedang musim lainnya tidak memberikan hasil. Kadang terkendala dengan cuaca yang kurang memungkinkan nelayan untuk melaut.

2. Ketidakmampuan wanita nelayan Kelurahan Bahu Lingkungan 1 untuk diversifikasi dan pengolahan ikan akibat kurangnya skill dan pengetahuan menjadi salah satu penyebab daya tahan ekonomi rumah tangga nelayan rendah. Di musim paceklik, nelayan tidak akan mendapatkan penghasilan apabila tidak memiliki mata pencaharian alternative, atau melibatkan keluarga untuk menghasilkan uang guna memenuhi berbagai kebutuhan rumah tangga.

Berdasarkan permasalahan yang dikemukakan, maka diperlukan pemberdayaan terhadap kelompok perempuan pesisir Kelurahan Bahu Lingkungan 1 melalui edukasi diversifikasi produk ikan deho / tongkol menjadi abon ikan.

\section{Tujuan dan Manfaat Kegiatan}

Tujuan program ini yaitu memberdayakan kelompok perempuan Kelurahan Bahu Lingkungan 1 Manado dalam mengolah/diversifikasi produk ikan tongkol menjadi abon. Adanya diversifikasi abon ikan tongkol ini diharapkan dapat meningkatan produksi olahan hasil perikanan, meningkatkan, mengembangkan SDM sehingga trampil dan mandiri secara ekonomi yang pada akhirnya dapat meningkatkan pendapatan keluarga nelayan.

\section{METODE PELAKSANAAN}

Sasaran Kegiatan Pengabdian

Mitra sasaran program ini adalah Kelompok perempuan yang berada di Kelurahan Bahu Lingkungan 1 Manado Kecamatan Malalayang Provinsi Sulawesi Utara, secara geografis terletak di pesisir pantai dengan potensi perikanan tangkap yang potensial untuk dikembangkan

\section{Lokasi Kegiatan Pengabdian}

Kegiatan pengabdian pada masyarakat ini dilaksanakan di Kelurahan Bahu Lingkungan 1, Kecamatan Malalayang Kota Manado Provinsi Sulawesi Utara. Karena situasi dan kondisi pandemic Covid-19, dimana tidak memungkinkan kerumunan orang dan melihat antusiasme masyarakat yang tinggi maka kegiatan ini dilaksanakan pada dua tempat dan waktu yang berbeda.

\section{Metode Yang Digunakan}

Metode pelatihan dilakukan berdasarkan metode pembelajaran orang dewasa (otodidak) dan dilaksanakan secara klasikal melalui diskusi kelompok secara terarah (FGD = Focus Group Discussion), penyuluhan dan pelatihan.

Penyuluhan dimaksudkan untuk merobah perilaku sumberdaya manusia (SDM) ke arah yang lebih baik dengan cara mengedukasi pengolah abon ikan dalam meningkatkan taraf kehidupan dengan usahanya sendiri, serta mengedukasi mereka untuk mengolah sumberdaya alamnya dengan bijaksana. Materi penyuluhan berisi; 1) Diversifikasi produk olahan ikan, 2) Sanitasi dan hygiene personal, 3) sarana pengolahan dan lingkungannya yang mempengaruhi mutu dan keamanan produk olahan abon ikan.

Setelah selesai materi penyuluhan, tahap selanjutnya adalah pelatihan pembuatan abon ikan. Kegiatan pelatihan dimaksud adalah praktek penerapan iptek yang terdiri dari:

a. Pengolahan /diversifikasi produk ikan deho dan ikan pelagis lainnya menjadi abon ikan

b. Penggunaan alat peniris minyak (spinner).

c. Pengemasan abon ikan dalam kemasan botol plastik

d. Pengujian tingkat kesukaan oleh panelis (ibu-ibu yang mengolah abon) 


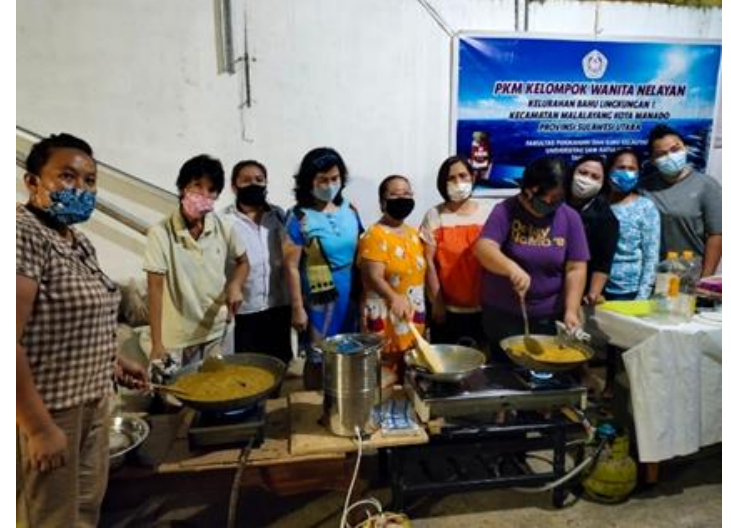

Gambar 1. Kegiatan pengolahan abon ikan

\section{HASIL DAN PEMBAHASAN}

Pemberdayaan merupakan suatu proses dalam melakukan perubahanperubahan yang terencana. Tahapan yang dilakukan antara lain adalah penyadaran masyarakat tentang keberlangsungan hidup mereka yang bukan saja sebagai makhluk individu tetapi juga kapasitas mereka sebagai makhluk sosial, budaya dan ekonomi, sehingga selayaknya dapat berpikir lebih luas tentang dampak yang harus dihadapi ketika permasalahan terjadi.

Kegiatan pemberdayaan perempuan kelurahan Bahu Lingkungan 1 Kecamatan Malalayang Provinsi Sulawesi Utara diawali dengan diskusi dan penyuluhan. Materi diskusi dan penyuluhan yang disampaikan antara lain: 1) diversifikasi produk olahan ikan, 2) Sanitasi dan hygiene personal, 3) Mutu dan keamanan pangan.

Kegiatan penyuluhan ini bertujuan merobah perilaku sumberdaya manusia (SDM) ke arah yang lebih baik dengan cara memberdayakan perempuan/ibu ibu yang ada di Kelurahan Bahu cara diversifikasi produk hasil perikanan antara lain pengolahan abon ikan.

Setelah dilakukan penyuluhan dilanjutkan dengan pelaksanaan pelatihan dan praktek pengolahan. Kegiatan pelatihan dimaksud adalah praktek penerapan iptek. Kegiatan ini dilakukan oleh tim pengabdian dibantu dengan 2 orang mahasiswa S1 tingkat akhir. Pelatihan dimaksud terdiri dari:

1. Praktek pengolahan abon ikan deho/tongkol dan ikan pelagis lainnya.
Pada sesi ini peserta pelatihan (Kelompok Lestari) diajari cara mengolah ikan deho/tongkol dan ikan pelagis lainnya menjadi abon ikan. Pembuatan abon merupakan salah satu alternatif pengolahan ikan. Hal ini dilakukan untuk mengantisipasi kelimpahan produksi ataupun untuk penganekaragaman produk perikanan. Berdasarkan SNI 01-3707-1995, abon merupakan hasil pengolahan yang berupa pengeringan bahan baku yang telah ditambahkan bumbu-bumbu untuk meningkatkan cita rasa dan memperpanjang daya simpan. Jenis ikan yang dibuat sebagai bahan baku jenis abon belum selektif, bahkan hampir semua jenis ikan dapat dijadikan abon. Namun demikian, akan lebih baik bila dipilih jenis ikan yang mempunyai serat yang kasar dan tidak mengandung banyak duri.

2. Praktek penggunaan alat peniris minyak. Penggunaan alat sederhana ini bertujuan agar mitra sasaran yaitu kelompok Lestari dapat menggunakan alat peniris minyak sederhana dan dapat melakukan proses produksi pengolahan abon ikan dengan waktu yang lebih singkat, lebih bersih dan terjamin mutunya.

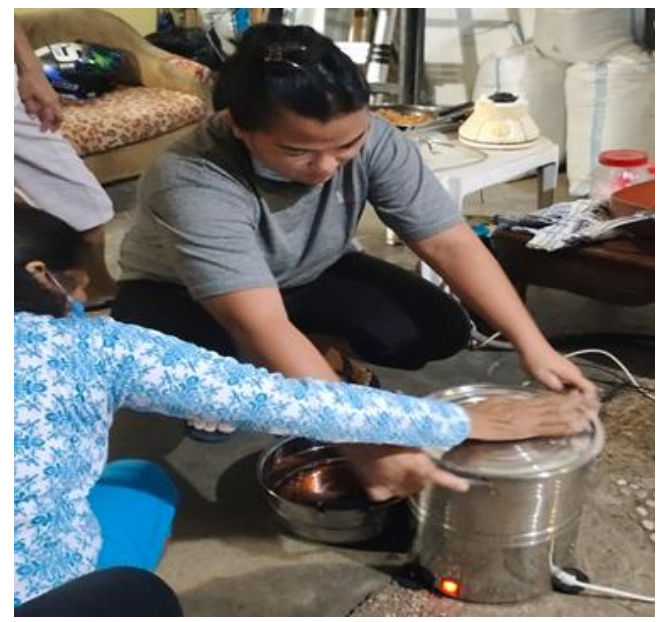

Gambar 2. Praktek penggunaan alat peniris minyak (spinner)

Prinsip kerja alat/mesin peniris minyak adalah bahan berminyak yang diletakkan di dalam keranjang bahan 
akan diputar oleh poros yang dihubungkan dengan motor listrik menggunakan $V$-Belt. Akibat dari gaya sentrifugal yang terjadi saat keranjang berputar, maka bahan akan bergerak menuju ke sisi-sisi keranjang. Bahan yang ukurannya lebih kecil daripada ukuran lubang keranjang termasuk minyak, akan bergerak keluar melewati keranjang dan jatuh di body spinner yang selanjutnya mengalir keluar dari body karena kemiringan alas body spinner. Dengan demikian, bahan yang tertinggal di dalam keranjang menjadi kering, renyah, dan siap dikemas karena kandungan minyak sudah banyak berkurang.

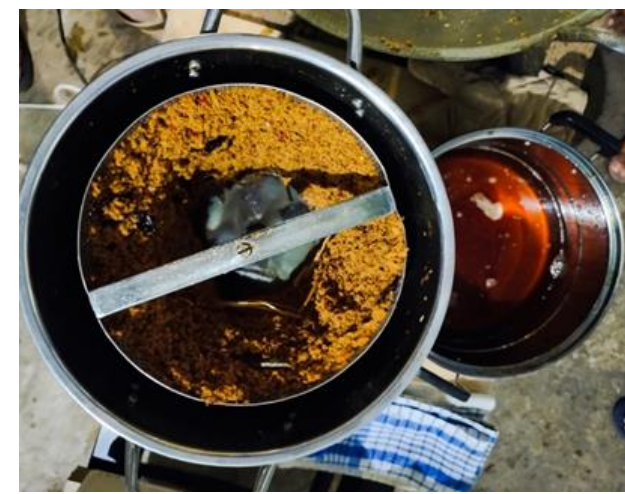

Gambar 3. Penirisan minyak

3. Setelah abon ikan selesai ditiris minyak, didingin-anginkan sebentar, dibagi menjadi dua bagian. Satu bagian disisihkan untuk dilakukan uji organoleptik (tingkat kesukaan) dan satu bagian lainnya kemudian dilanjutkan dengan praktek pengemasan. Kemasan/wadah yang digunakan adalah toples plastik kecil. Abon ikan yang akan dikemas ditimbang terlebih dahulu sebanyak $\pm 150 \mathrm{~g}$.

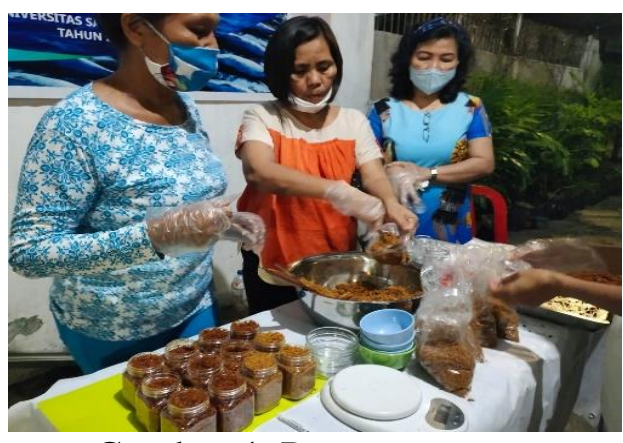

Gambar 4. Pengemasan

4. Tahap selanjutnya adalah praktek penilaian organoleptik berdasarkan tingkat kesukaan panelis. Panelis terdiri dari anggota kelompok Lestari dan beberapa panelis lainnya yang turut serta dalam praktek/pelatihan. Panelis sebanyak 20 (dua puluh) orang diberikan score sheet dengan level penilaian amat sangat suka, sangat suka, suka, agak tidak suka dan tidak suka. Panelis diminta untuk mencentang atribut penilaian sesuai dengan tingkatan atau level yang mereka sukai. Atribut yang dinilai yaitu rasa, tekstur, aroma dan kenampakan abon ikan. Hasil penilaian panelis adalah sebagai berikut:

a. Rasa; Dari 20 orang panelis rata-rata memberikan respon sangat suka terhadap rasa abon ikan. Rasa merupakan faktor yang penting dalam menentukan penerimaan atau penolakan konsumen terhadap suatu bahan pangan. Meskipun tekstur bahan pangan baik namun jika rasanya tidak enak maka konsumen akan menolak produk tersebut (Winarno, 2004). Menurut Soekarto (1985), rasa makanan yang kita kenal sehari-hari sebenarnya bukanlah satu tanggapan, melainkan campuran dari tanggapan cicip, bau, dan trigeminal yang diramu oleh kesan kesan lain seperti penglihatan, sentuhan, dan pendengaran. Jadi, kalau kita menikmati atau merasakan makanan, sebenarnya kenikmatan tersebut diwujudkan bersama-sama oleh kelima indera. Peramuan rasa itu ialah suatu sugesti kejiwaan terhadap 
makanan yang menentukan nilai pemuasan orang yang memakannya.

b. Tekstur; Untuk nilai tekstur panelis juga rata-rata memberikan nilai sangat suka yaitu sebanyak 14 orang. 6 orang panelis lainnya memberikan nilai suka. Penilaian tekstur abon ikan penting dilakukan karena merupakan salah satu ciri yang membedakannya dengan abon dari bahan lainnya.

c. Aroma; Aziz (2012), menyatakan bahwa aroma adalah salah satu komponen cita rasa yang sangat berpengaruh pada makanan. Aroma merupakan hasil dari respon indra penciuman akibat dari menguapnya senyawa tertentu yang sedikit larut lemak dan direspon dengan baik oleh indra penciuman dan dikenali oleh sistem tubuh sebagai aroma tertentu. Penilaian panelis terhadap aroma abon ikan rata-rata memberikan nilai yang amat sangat suka, yakni sebanyak 17 orang.

d. Kenampakan; Nilai kenampakan juga memberikan hasil yang hamper sama dengan aroma. Sebanyak 16 orang panelis memberikan nilai amat sangat suka. Kenampakan dipengaruhi oleh beberapa faktor diantaranya adalah proses penggorengan. Proses pengorengan menghasilkan warna kuning kecoklatan. Adapun warna kecolatan yang ditimbulkan disebabkan adanya proses karamelisasi. Karamel adalah substansi berasa manis, berwarna coklat dan merupakan campuran dari beberapa senyawa yang mirip karbohidrat. Sukrosa akan mengalami karamelisasi apabila suhu yang digunakan di atas titik lebur sukrosa. Reaksi maillard adalah reaksi karbohidrat, khususnya gula pereduksi dan gugus amina primer. Hasil reaksi tersebut menghasilkan bahan berwarna coklat yang dikehendaki atau kadang juga menjadi pertanda penurunaan mutu (Rohmawati et al, 2016)
Secara keseluruhan, untuk uji tingkat kesukaan panelis rata-rata penilaian adalah amat sangat suka dan sangat suka terhadap produk abon ikan yang dihasilkan.

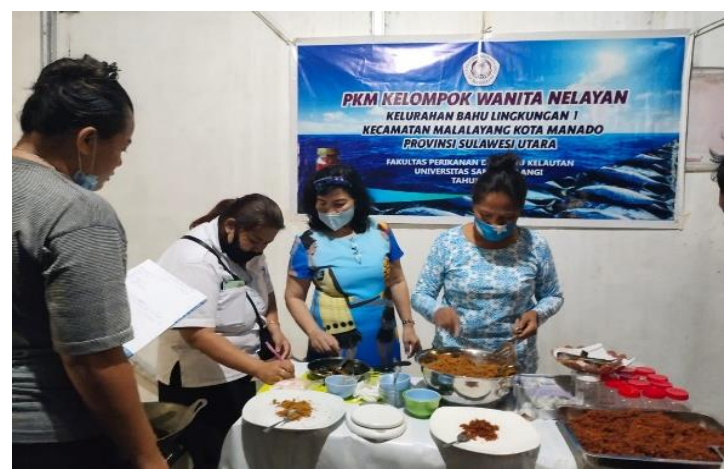

Gambar 5. Pengujian organoleptik oleh peserta pelatihan

\section{KESIMPULAN DAN SARAN Kesimpulan}

Pemberdayaan kaum perempuan melalui edukasi diversifikasi produk hasil perikanan merupakan salah satu alternatif pengembangan matapencaharian berbasis teknologi tepat guna. Hal ini merupakan tuntutan dan kebutuhan yang harus dilakukan, khususnya untuk masyarakat pesisir. Upaya ini memiliki relevansi dengan penanganan kemiskinan. Pemanfaatan teknologi dan peralatan tepat guna dalam pengembangan mata pencaharian alternatif merupakan sarana untuk menunjang optimalisasi aktivitas usaha dan menjamin agar peluang kerja di kawasan pesisir tetap tersedia bagi mereka yang membutuhkan. Struktur sosial dan struktur ekonomi daerah pesisir memberi ruang yang luas bagi perempuan pesisir untuk mengembangkan mata pencaharian alternatif.

\section{Saran}

Program pemberdayaan masyarakat pesisir seyogyanya menjadi perhatian serius. Partisipasi perguruan tinggi, korporasi, dan pihak-pihak terkait lainnya diperlukan dalam mengembangkan teknologi tepat guna yang efektif untuk mengelola potensi sumberdaya pesisir-laut 
sebagai basis kegiatan ekonomi yang diarahkan akan menjadi matapencaharian alternatif bagi perempuan pesisir.

\section{DAFTAR PUSTAKA}

Dewayanti, Ratih dan Erna Ermawati Chotim. 2004. Marjinalisasi dan Eksploitasi Perempuan Usaha Mikro di Pedesaan Jawa. Bandung: Yayasan Akatiga.

[DKP, Sulut]. Dinas Kelautan dan Perikanan Sulawesi Utara. Laporan Tahunan Dinas Kelautan dan Perikanan Propinsi Sulawesi Utara.

Hikmat, 2004. Strategi Pemberdayaan Masyarakat. Bandung (ID): Humaniora utama.

Ismail A.M., Dhanang E. P., 2017. Inovasi Pembuatan Abon Ikan Cakalang Dengan Penambahan Jantung Pisang Agritech : Vol. XIXNo. 1 Juni 2017: 45-54, ISSN: 1411-1063. Jember; https://media.neliti.com/media/public ations/217400-inovasi-pembuatanabon-ikan-cakalang-den.pdf

[LPM Unsrat] Lembaga Pengabdian kepada Masyarakat. 2017. Kinerja Lembaga Pengabdian kepada Masyarakat Universitas Sam Ratulangi Manado. 